\title{
Trastuzumab inhibits pituitary tumor cell growth modulating the TGFB/SMAD2/3 pathway
}

\author{
Juan Pablo Petiti1,*, Liliana del Valle Sosa1,*, Florencia Picech1, Gabriela Deisi Moyano Crespo1, \\ Jean Zander Arevalo Rojas', Pablo Anibal Pérez', Carolina Beatriz Guido', Carolina Leimgruber', \\ María Eugenia Sabatino', Pedro García², Verónica Bengio3, Francisco Roque Papalini4, Paula Estario5, \\ Celina Berhard6, Marcos Villarreal7, Silvina Gutiérrez¹, Ana Lucía De Paul1, Jorge Humberto Mukdsi and \\ Alicia Inés Torres ${ }^{1}$
}

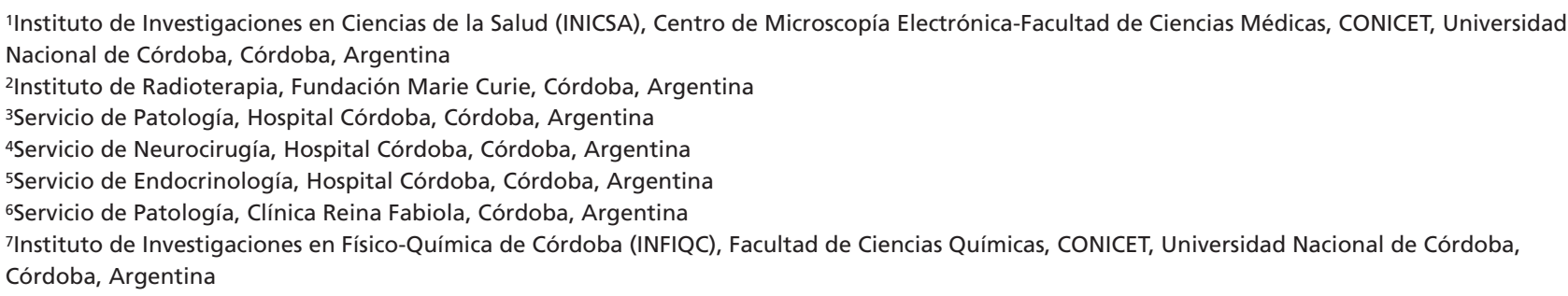

\begin{abstract}
In pituitary adenomas, early recurrences and resistance to conventional pharmacotherapies are common, but the mechanisms involved are still not understood. The high expression of epidermal growth factor receptor 2 (HER2)/extracellular signalregulated kinase (ERK1/2) signal observed in human pituitary adenomas, together with the low levels of the antimitogenic transforming growth factor beta receptor 2 (TBR2), encouraged us to evaluate the effect of the specific HER2 inhibition with trastuzumab on experimental pituitary tumor cell growth and its effect on the antiproliferative response to TGFB1. Trastuzumab decreased the pituitary tumor growth as well as the expression of ERK1/2 and the cell cycle regulators CCND1 and CDK4. The HER2/ERK1/2 pathway is an attractive therapeutic target, but its intricate relations with other signaling modulators still need to be unraveled. Thus, we investigated possible cross-talk with TGFB signaling, which has not yet been studied in pituitary tumors. In tumoral GH3 cells, co-incubation with trastuzumab and TGFB1 significantly decreased cell proliferation, an effect accompanied by a reduction in ERK $1 / 2$ phosphorylation, an increase of SMAD2/3 activation. In addition, through immunoprecipitation assays, a diminution of SMAD2/3ERK1/2 and an increase SMAD2/3-TGFBR1 interactions were observed when cells were co-incubated with trastuzumab and TGFB1. These findings indicate that blocking HER2 by trastuzumab inhibited pituitary tumor growth and modulated HER2/ERK $1 / 2$ signaling and consequently the anti-mitogenic TGFB1/TBRs/SMADs cascade. The imbalance between HER2 and TGFBRs expression observed in human adenomas and the response to trastuzumab on experimental tumor growth may make the HER2/ERK1/2 pathway an attractive target for future pituitary adenoma therapy.
\end{abstract}

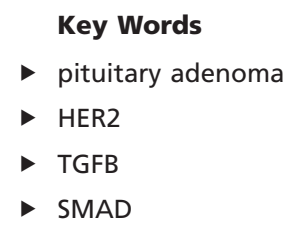

Endocrine-Related Cancer (2018) 25, 837-852 


\section{Introduction}

Pituitary adenomas occur in around $10-15 \%$ of all intracranial neoplasms, but only a few of these are symptomatic according to estimations from various clinical studies (Asa \& Ezzat 1998, Tomita \& Gates 1999, Kaltsas et al. 2005). Although the vast majority are benign, between 25 and $55 \%$ of pituitary adenomas are invasive, with some exhibiting clinically aggressive behavior (Kaltsas \& Grossman 1998, Ironside 2003). The initial treatment of pituitary adenomas is based on protocols designed for each tumor type. Dopamine agonists have become the initial treatment for most patients with prolactinsecreting tumors, whereas for growth hormone-producing tumors, surgical resection is the first-line therapy, while somatostatin analogs are used in patients with large tumors. However, $20 \%$ of patients are refractory to these medical treatments (Di Ieva et al. 2014).

In normal pituitary tissue, the stimulatory and inhibitory growth signals are finely regulated, with alterations in these being directly or indirectly associated with tumorigenesis. The transforming growth factor beta 1 (TGFB1) and epidermal growth factor (EGF) have opposite functions but play essential roles in tumor development by converting them into attractive therapeutic targets (Yarden \& Sliwkowski 2001). The human EGF receptor family consists of four members (HER/ERBB1-4) (Roskoski 2014), with the HER receptors having of an extracellular domain, a single hydrophobic transmembrane segment and an intracellular domain with protein kinase activity (Dworakowska et al. 2009). Dimerization of the HER receptors leads to the induction of kinase activity, which as a result, a number of tyrosine residues at the $\mathrm{C}$ terminal end of the HER molecules become phosphorylated. The two major signaling pathways activated by HER receptors are the MEK/ERK and PI3K-AKT pathways (Yarden \& Sliwkowski 2001), which both participate in cell proliferation, angiogenesis, cell adhesion, cell motility and tumorigenesis (Seshacharyulu et al. 2012). Certain components of these pathways may be activated/ inactivated by mutations or epigenetic silencing, and dysregulation of the components of these cascades can contribute to resistance to other pathway inhibitors and chemotherapeutic drug resistance (McCubrey et al. 2012). In addition, the MEK/ERK and PI3K/AKT cascades are often activated by genetic alterations in upstream signaling molecules such as receptor tyrosine kinases. In this way, several malignancies are associated with the mutation or increased expression of members of the HER family, including lung, breast, stomach, colorectal, head, neck and pancreatic carcinomas, as well as glioblastomas (Roskoski 2014). HER2 is a more potent oncoprotein than the other HERs, and thus, blocking their action might inhibit a myriad of mitogenic pathways affecting the HER2-expressing tumor cells (Onishi et al. 2016). Although several new strategies are currently being developed trastuzumab (a drug designed to block the receptor HER2) has been the first to attain clinical use, mainly for the treatment of metastatic breast cancer (Baselga et al. 1996, Cobleigh et al. 1999).

The expression of HER2 has been reported in pituitary tumors (Ezzat et al. 1997, Nose-Alberti et al. 1998, Roncaroli et al. 2003), including prolactinomas (Vlotides et al. 2009), and it has been demonstrated that overexpression of constitutively active HER 2 markedly induces PRL expression and secretion as well as cell growth in rat GH3 lactotroph tumor cells, effects that are blocked by lapatinib, a dual tyrosine kinase inhibitor of both epidermal growth factor receptors HER1 and HER2 (Fukuoka et al. 2011). For signaling pathways activated by HER2, there are studies showing increases in MEK/ERK activity in pituitary tumors (Cakir \& Grossman 2009). However, although the MEK/ERK signaling pathway plays a central role in the regulation of cell proliferation, differentiation and survival, its exact functional relevance in complex signaling network, pituitary tumorigenesis and resistance to conventional medical treatments is not fully understood, but it may enable the development of attractive novel strategies for treating common tumors.

It is well known that the MEK/ERK is not a unidirectional cascade of protein kinases, but forms a complex signaling network with many interactions including inhibitory cascades. Recently, we demonstrated that the TGFB1-antimitogenic effect in pituitary tumor cells was attenuated by the MEK/ERK1/2 pathway by modulating SMAD2/3 phosphorylation (Petiti et al. 2015). TGFB1 signaling is mediated by TGFB type 1 receptor (TBR1) and TBR2. Upon TGFB binding, the TBR2 receptors activate the TBR1 receptors, inducing phosphorylation of mothers against the decapentaplegic homologs SMAD2 and SMAD3, which form trimers with Smad4 that translocate into the nucleus, where they regulate the expression of genes that control cell cycle progression (Kang et al. 2009).

One of the principal obstacles to the development of new antitumoral therapies is that the inhibition of a unique signaling pathway essential for the cell survival is a pharmacological strategy made ineffective due to the tumoral cells utilizing alternative cascades and promoting a paradoxical enrichment of resistant cells. In this sense, 
the study of the crosstalk between the signals from HER and TBRs in pituitary tumors might permit a better understanding of the altered balance between the positive and negative regulators that control the pituitary tumor growth, which may condition the therapeutic response. The HER/ERK1/2 pathway is an attractive therapeutic target as an alternative medical therapy for pituitary tumors. In order to safely choose the candidate drugs, their intricate relations, positive and negative feedback loops and signaling modulators must be thoroughly understood. In the present study, our objectives were to determine the effect of the specific HER2 receptor inhibitor trastuzumab on pituitary tumor growth and to evaluate its impact on the antiproliferative response to TGFB1.

\section{Materials and methods}

\section{Human pituitary tissues and tumors}

The study group included 20 patients diagnosed with pituitary adenomas from Hospital Córdoba, Sanatorio Allende or Clínica Reina Fabiola, Córdoba, Argentina in the period 2004-2015. Pituitary tumors were obtained from consented patients who had not been treated with radiotherapy by trans-sphenoidal surgery after full endocrine preoperative evaluation. The fresh human pituitary adenoma tissue at the time of surgery was obtained from 12 functioning adenomas (four PRLsecreting, six GH-secreting and two ACTH-secreting tumors) and 8 non-functioning adenomas. The samples were processed for immunohistochemical analysis (Tables 1 and 2). In addition, a group of tumor samples were processed for Western blot. Non-tumor human adenohypophyses $(n=6)$ were obtained from autopsies from patients with no evidence of endocrine abnormality and examined histologically. The present project was approved by the Ethics Committee (Repis No 37/2014).

\section{Animal model}

Three-month-old Fischer-344 male rats were bred and housed at the Animal Research Facility of the INICSACONICET-School of Medicine, National University of Córdoba, under controlled temperature $\left(21 \pm 3^{\circ} \mathrm{C}\right)$ and lighting conditions (14-h light:10-h darkness cycle), with free access to commercial rodent food and tap water. Forty-three rats were randomly assigned to four groups: Group C $(n=13)$ : intact animals as control; Group E $(n=13)$ : intact animals treated with estradiol benzoate pellets (30 mg, Sigma-Aldrich), as described by
Table 1 Clinicopathologic and immunohistochemical characteristics of human pituitary adenomas.

\begin{tabular}{|c|c|c|c|c|}
\hline Case & Gender/age & $\begin{array}{l}\text { Clinicopathologic } \\
\text { classification }\end{array}$ & IHC & Ki67 (\%) \\
\hline 1 & $F / 20$ & Functioning & PRL & 1 \\
\hline 2 & $F / 38$ & Functioning & PRL & 1 \\
\hline 3 & $F / 31$ & Functioning & PRL & 1 \\
\hline 4 & $F / 26$ & Functioning & PRL & 1 \\
\hline 5 & $\mathrm{~F} / 58$ & Functioning & $\mathrm{GH}$ & 3 \\
\hline 6 & $F / 37$ & Functioning & $\mathrm{GH}$ & 2 \\
\hline 7 & $\mathrm{~F} / 57$ & Functioning & $\mathrm{GH}$ & 2 \\
\hline 8 & $F / 27$ & Functioning & $\mathrm{GH}$ & 1 \\
\hline 9 & $\mathrm{M} / 31$ & Functioning & $\mathrm{GH}$ & 1 \\
\hline 10 & $\mathrm{~F} / 64$ & Functioning & $\mathrm{GH}$ & N.D. \\
\hline 11 & $F / 32$ & Functioning & АCTH & 5 \\
\hline 12 & $\mathrm{~F} / 62$ & Functioning & АCTH & 2 \\
\hline 13 & $\mathrm{M} / 63$ & Non-functioning & Negative & 5 \\
\hline 14 & $\mathrm{M} / 44$ & Non-functioning & Negative & 1 \\
\hline 15 & $\mathrm{~F} / 45$ & Non-functioning & Negative & 3 \\
\hline 16 & $M / 58$ & Non-functioning & Negative & 3 \\
\hline 17 & $\mathrm{~F} / 68$ & Non-functioning & Negative & 2 \\
\hline 18 & $\mathrm{M} / 56$ & Non-functioning & Negative & 5 \\
\hline 19 & $\mathrm{~F} / 62$ & Non-functioning & Negative & 1 \\
\hline 20 & $\mathrm{M} / 50$ & Non-functioning & Negative & 1 \\
\hline
\end{tabular}

ACTH, adenocorticotroph hormone; $F$, female; $G H$, growth hormone; $M$, male; N/D, no data; PRL, prolactin.

Sahores et al. (2013), for 45 days to induce a PRL pituitary tumor development (Asa \& Ezzat 2002); Group T ( $n=4)$ : animals treated with trastuzumab $6 \mathrm{mg} / \mathrm{kg}$ (Herceptin, Roche) during 15 days; Group E $+\mathrm{T}(n=13)$ : during the last 15 days before the end of the estradiol treatment, the rats received trastuzumab. The treatments with trastuzumab consisted of two intraperitoneal injections given once a week following protocols previously reported (Guler et al. 2009, Eryilmaz et al. 2015, Hendry et al. 2016).

All animals were treated in agreement with the Guide for the Care and Use of Laboratory Animals, published by the United States National Institutes of Health (1996), and experiments were approved by the Institutional Animal Care Committee of the School of Medicine, National University of Córdoba.

\section{Immunohistochemistry}

Paraffin-embedded pituitary glands were processed by immunohistochemistry for HER2, pHER2, TBR1, TBR2 and Ki67. The sections were blocked and incubated ON with anti-HER2 (1:300: Dako), anti-pHER2 (1:300; Santa Cruz Biotechnology), anti-TBR1 (1:200; Santa Cruz Biotechnology), anti-TBR2 (1:200; Santa Cruz Biotechnology) or anti-Ki67 (1:75; BD Biosciences, San Jose, CA, USA) at $4^{\circ} \mathrm{C}$. The sections were then incubated with biotinylated secondary antibodies (Vector Laboratories, 
Table 2 Immunohistochemical characteristics of human pituitary samples.

\begin{tabular}{|c|c|}
\hline Case & Gender/age \\
\hline 1 & $\mathrm{~F} / 20$ \\
\hline 2 & $F / 38$ \\
\hline 3 & $\mathrm{~F} / 31$ \\
\hline 4 & $\mathrm{~F} / 26$ \\
\hline 5 & $F / 58$ \\
\hline 6 & $\mathrm{~F} / 37$ \\
\hline 7 & $\mathrm{~F} / 57$ \\
\hline 8 & $F / 32$ \\
\hline 9 & M/63 \\
\hline 10 & $M / 44$ \\
\hline 11 & $F / 45$ \\
\hline 12 & M/58 \\
\hline 13 & $\mathrm{~F} / 54$ \\
\hline 14 & M/35 \\
\hline 15 & M/57 \\
\hline
\end{tabular}

\begin{tabular}{l} 
Clinicopathologic classification \\
\hline Functioning \\
Functioning \\
Functioning \\
Functioning \\
Functioning \\
Functioning \\
Functioning \\
Functioning \\
Non-functioning \\
Non-functioning \\
Non-functioning \\
Non-functioning \\
Non-tumor tissue \\
Non-tumor tissue \\
Non-tumor tissue
\end{tabular}

\begin{tabular}{l} 
IHC \\
\hline PRL \\
PRL \\
PRL \\
PRL \\
GH \\
GH \\
GH \\
ACTH \\
Negative \\
Negative \\
Negative \\
Negative \\
N/A \\
N/A \\
N/A
\end{tabular}

\begin{tabular}{c}
\hline $\mathbf{K i 6 7}(\%)$ \\
\hline 1 \\
1 \\
1 \\
1 \\
3 \\
2 \\
2 \\
5 \\
5 \\
1 \\
3 \\
3 \\
N/A \\
N/A \\
N/A
\end{tabular}

\begin{tabular}{c}
\hline HER2 (\%) \\
\hline $10++$ \\
$44+$ \\
$27+$ \\
0 \\
$79+++$ \\
0 \\
0 \\
$80+++$ \\
0 \\
$98+++$ \\
0 \\
0 \\
0 \\
0 \\
$5+$ \\
\hline
\end{tabular}

\begin{tabular}{c}
\hline PHER2 \\
\hline 0 \\
N/D \\
N/D \\
0 \\
36.1 \\
0 \\
N/D \\
59.1 \\
10.5 \\
49.5 \\
N/D \\
N/D \\
N/D \\
N/D \\
0 \\
\hline
\end{tabular}

\begin{tabular}{|c|c|}
\hline TBRI (\%) & TBRII (\%) \\
\hline 100 & 100 \\
\hline 100 & 94 \\
\hline 100 & 0 \\
\hline 100 & 1 \\
\hline 51 & 100 \\
\hline 52 & 40 \\
\hline 94 & 0 \\
\hline 40 & 72.8 \\
\hline 16 & $N / D$ \\
\hline 26 & 100 \\
\hline 11 & 0 \\
\hline 0 & 80 \\
\hline 100 & 80 \\
\hline 28 & 80 \\
\hline 60 & 90 \\
\hline
\end{tabular}

Staining score: $+=$ low $++=$ moderate, $+++=$ strong

ACTH, adenocorticotroph hormone; F, female; GH, growth hormone; M, male; N/D, no data; PRL, Prolactin.

Burlingame, CA, USA) and streptavidin (Dako). The slides from three animals of each experimental condition were photographed in randomly chosen fields at 400x. The quantification of the expressions was assessed by subsequent manual counting of positive and negative cells per highpower visual field, with more than 2000 immunoreactive cells being examined.

\section{Detection of apoptosis by DNA nick-end labeling}

Nick-end labeling was detected using the TUNEL technique, as previously reported (Palmeri et al. 2009), following the manufacturer's protocol (In Situ Cell Death Detection Kit; Roche). The slides were observed using a Zeiss Axiostar plus microscope at 400x.

\section{Cell culture}

The rat GH3 lactosomatotroph pituitary tumor cell line (ATCC-BAA-1926) was used as an in vitro pituitary tumoral model (McIntyre et al. 2004). The cells were cultured in Ham's F-12 Nutrient Mixture medium supplemented with fetal bovine and horse serum and antibiotics. After 3 days of culture and with a confluence of $70 \%$, the cells were submitted to different experimental protocols. Cell cultures were treated with TGFB1 $(4 \mathrm{ng} / \mathrm{mL}$, Sigma), trastuzumab $(100 \mu \mathrm{g} / \mathrm{mL})$ or the combination of both factors for $30 \mathrm{~min}$ or $24 \mathrm{~h}$.

\section{Flow cytometry staining for detection of Ki67}

To analyze GH3 proliferation by Ki67 detection, the cells were detached using TrypLE Express (Gibco), washed twice with PBS and fixed overnight with icecold $70 \%$ ethanol. After washing, cells were incubated with anti-Ki67 (1:75; BD Biosciences) at $37^{\circ} \mathrm{C}$ for $45 \mathrm{~min}$, followed by incubation with secondary antibody AlexaFluor 488 (1:1000; Invitrogen) for $1 \mathrm{~h}$ at $37^{\circ} \mathrm{C}$. Finally, GH3 cells were suspended in PBS and run on a flow cytometer (FACSCanto II, BD Biosciences). The data obtained were analyzed by FlowJo V10 software (Tree Star, Inc, Ashland, OR, USA).

\section{Immunocytochemical detection of BrdU uptake}

GH3 cells at the DNA-synthesizing stage were identified by the immunocytochemical detection of BrdU. After of stimulation with the different reagents, BrdU (200 nM) was added for an additional $4 \mathrm{~h}$. The cells attached to coverslips were fixed in $4 \%$ formaldehyde in PBS for $2 \mathrm{~h}$ at room temperature (RT) and BrdU incorporation detection was performed as described by Ferraris et al. (2014).

\section{Immunoprecipitation}

Protein extraction of tumoral pituitary cells $(1 \mathrm{mg}$ of protein) was carried out according to previous protocols (Sosa Ldel et al. 2013), which was then subjected to immunoprecipitation using specific anti-pSMAD2/3 $(5 \mu \mathrm{g} / \mathrm{mL}$; Santa Cruz Biotechnology) or Trastuzumab $(5 \mu \mathrm{g} / \mathrm{mL})$. The immune complexes were adsorbed and precipitated using Protein A-Sepharose beads (SigmaAldrich), washed 3 times with lysis buffer and denatured by boiling for $5 \mathrm{~min}$ in the sample buffer. Parallel immunoprecipitations were performed using a nonimmune goat serum, which verified the specificity of 
the bands detected by Western blotting using anti-TBR1 (1:200), anti-pSMAD2/3 (1:1000 Cell Signaling) and anti-pERK1/2 (1:1000 Cell Signaling).

\section{Analysis of cell-surface proteins by biotinylation}

The cell-surface proteins were labeled according manufacturer's protocol (Pierce Cell Surface Protein Isolation Kit (Prod\#89881)). Briefly, GH3 and MCF7 cell cultures were washed three times with ice-cold PBS buffer, $\mathrm{pH} 8$, and then incubated with membraneimpermeable sulfo-NHS-biotin at a final concentration of $0.3 \mathrm{mg} / \mathrm{mL}$ in $\mathrm{PBS}, \mathrm{pH} 8$, at $4^{\circ} \mathrm{C}$ for $20 \mathrm{~min}$. After biotinylation, the cultures were washed three times with ice-cold PBS, and harvested with lysis buffer containing 1.25\% Igepal CA-630, $1 \mathrm{mM}$ EDTA, $2 \mathrm{mM}$ PMSF, $10 \mu \mathrm{g} / \mathrm{mL}$ leupeptin and $10 \mu \mathrm{g} / \mathrm{mL}$ aprotinin (all inhibitors were from Sigma). The cellular extracts were sonicated and incubated with avidin-agarose beads (Pierce) for $2 \mathrm{~h}$ at $4^{\circ} \mathrm{C}$. Then, the extracts were centrifuged at $500 \mathrm{~g}$ for $10 \mathrm{~min}$ at $4^{\circ} \mathrm{C}$, the supernatant $(200 \mu \mathrm{L})$ was separated and the pellet was washed three times with $1 \mathrm{~mL}$ of lysis buffer. The proteins from the supernatant fractions were run in $7.5 \%$ acrylamide gel. Both pellet and supernatant fractions were analyzed by Western blot using specific antibodies.

\section{Western blot analysis}

Protein extracts $(30 \mu \mathrm{g})$ were separated in a polyacrylamide gel (Sigma-Aldrich), transferred to a nitrocellulose membrane and nonspecific binding blocked with PBS-5\% non-fat dried milk at RT. The membranes were then rinsed and incubated overnight with anti-HER2 (1:1000), antipHER2 (1:350), anti-TBR1 (1:300), anti-TBR2 (1:300), antiCCND1 (1:300, Santa Cruz Biotechnology), anti-CDK4 (1:400, Abcam), anti-pSMAD2/3 (1:1000 Cell Signaling), anti-SMAD2/3 (1:1000, Cell Signaling), anti-TERK1 (1:500, Santa Cruz Biotechnology), anti-pERK1/2 (1:1000, Cell Signaling) or anti-b-Actin (1:4000; Sigma-Aldrich).

The blots were incubated with HPRT-conjugated bovine anti-goat (1:2500; Santa Cruz Biotechnology), goat anti-mouse (1:2500, Jackson ImmunoResearch) or goat anti-rabbit secondary antibodies (1:5000, BioRad). The membranes were thoroughly rinsed in TBS $0.1 \%$ Tween 20 and the HPRT-coupled secondary antibody was revealed with enhanced chemiluminescence Western blotting detection reagents (GE Healthcare). Emitted light was captured on Hyperfilm (GE Healthcare).

\section{Confocal laser scanning microscopy}

Pituitary cells were fixed in $4 \%$ formaldehyde, permeabilized in $0.25 \%$ Triton X-100 in PBS, blocked for $1 \mathrm{~h}$ in PBS 3\% BSA and incubated with anti-HER2 (1:200) for $1 \mathrm{~h}$. Then, cells were incubated with Alexa Fluor 488 antirabbit antibody (1:2000; Invitrogen) for $1 \mathrm{~h}$. Images were obtained using the inverted confocal laser scanning microscope FluoView FV 1200 (Olympus). Serial z-axis sections were collected with an X60 objective and analysis of the confocal microscopy images was carried out using FV10-ASW 1.6 Viewer software.

\section{Immunogold electron microscopy}

The subcellular localization of the TGFB receptors in pituitaries from rats was examined by an ultrastructural immunocytochemical technique using protocols previously standardized in our laboratory (Petiti et al. 2009). The grids were incubated with anti-TBR1 (1:300) or anti-TBR2 (1:300) overnight at $4^{\circ} \mathrm{C}$, and then with anti-mouse or antirabbit secondary antibodies conjugated to $15 \mathrm{~nm}$ (Electron Microscopy Science, Hatfield, PA, USA) colloidal gold particles (1:30). The following controls were performed: (1) replacement of primary antiserum with PBS 1\% BSA and (2) replacement of primary antiserum with diluted preimmune serum followed by the secondary antibody. Then, the sections were examined in a Zeiss LEO 906-E transmission electron microscopy (TEM) (Zeiss, Oberkochen, Germany) and photographed with a megaview III camera (Olympus).

\section{Correlative light and electron microscopy}

Correlative light and electron microscopy (CLEM) was carried out on ultrathin cryo-sections by applying the Tokuyasu technique as described by Oorschot et al. (2014). Briefly, GH3 cells were fixed in $2 \%$ paraformaldehyde (Sigma-Aldrich) and $0.2 \%$ glutaraldehyde (Electron Microscopy Science) for $2 \mathrm{~h}$, embedded in $12 \%$ gelatin, infiltrated with $2.3 \mathrm{M}$ sucrose (Sigma-Aldrich) overnight at $48^{\circ} \mathrm{C}$, frozen in liquid nitrogen and sectioned at $-120^{\circ} \mathrm{C}(100 \mathrm{~nm}$ cryosections $)$ with a cryo-ultramicrotome RMC PowerTome-XL (RMC Boeckeler, Tucson, AZ, USA). Flat ribbons of $100 \mathrm{~nm}$ thick cryo-sections, collected with $1.15 \mathrm{M}$ sucrose and $1 \%$ methylcellulose (Sigma-Aldrich) were transferred on formvar-coated $100-\mu \mathrm{m}$ mesh hexagonal nickel grids (Electron Microscopy Science). 
For immunolabeling, samples were incubated on $2 \%$ gelatin in PBS for $20 \mathrm{~min}$ at $37^{\circ} \mathrm{C}$, blocked, incubated with anti-HER2 1:50 ON at $4^{\circ} \mathrm{C}$, rinsed and incubated with anti-rabbit Alexa-Fluor 594 (Invitrogen) for $1 \mathrm{~h}$ at $37^{\circ} \mathrm{C}$ in the presence of DAPI (Sigma-Aldrich). For immunogold labeling, grids were incubated with gold-conjugated protein-A $1: 15$ at $37^{\circ} \mathrm{C}$ for $1 \mathrm{~h}$.

For fluorescence light microscopy (FLM), grids layered with a $200 \mathrm{~nm}$ coat of $2 \%$ methylcellulose were mounted between a microscope slide and coverslip with 50\% glycerol in water. For TEM, grids were unmounted, washed in Milli-Q water and incubated for $5 \mathrm{~min}$ in $0.4 \%$ uranyl acetate and $1.8 \%$ methylcellulose. Fluorescence images were obtained using a FluoView FV 1200 microscope and EM images using a Zeiss LEO 906-E TEM. The analysis was carried out with ImageJ software.

\section{Double-immunohistochemistry on pituitary cryosections}

To assess co-expression of Ki67/PRL, Ki67/GH, Ki67/ ACTH and Trastuzumab-HER2/PRL, additional sets of pituitaries from different experimental conditions were used for confocal microscopy. Pituitary semi-thin cryosections were obtained by the Tokuyasu technique as described earlier. Then, the pituitary slices were incubated ON with anti-PRL (1/3000), anti-GH (1/3000), anti-ACTH (1/1000), anti-Ki67 (1/50) or Trastuzumab $(1 / 1000)$ at $4^{\circ} \mathrm{C}$. These slices were washed and incubated with FITC anti-human, Alexa 594 anti-rabbit or Alexa 488 anti-mouse secondary antibodies (1:3000; Dako, Invitrogen) for $1 \mathrm{~h}$ and with DAPI for $10 \mathrm{~min}$. The images were then obtained using a FluoView FV 1200 microscope. The analysis of the images was carried out using ImageJ software.

\section{Computational structural analysis}

The crystal structures and amino acid sequences of the extracellular region of rat sHER2 (code: 1n8y) and human sHER2 (code1: n8z) (Cho et al. 2003) were downloaded from the Protein Data Bank (www.rcsb. org) and superposition of the structures was calculated with the program ProFit (http://www.bioinf.org.uk/ software/profit/). Sequence alignment was performed with ClustalX (Larkin et al. 2007), molecular images were created with VMD (Humphrey et al. 1996) and the effect of change of the amino acid sequence on binding affinity was calculated with MutaBind (Li et al. 2016).

\section{Statistical analysis}

The experimental points represented the mean \pm S.E.M. of three replicates measured in three independent cell cultures. A statistical analysis was carried out using the $t$-test or ANOVA followed by the Fisher test using the InfoStat program. Significance levels were chosen as $P<0.05$.

\section{Results}

\section{Expression of HER2 and TBRs in human pituitary adenomas}

To investigate the protein expression of HER2 and TBRs in normal pituitaries $(n=6)$ and in different types of human pituitary adenoma samples (Table $1, n=20$ ), we examined these receptors by immunohistochemistry (IHC, $n=12$ ) or Western blot (WB, $n=8$ ) in nonfunctioning and functioning tumors. As shown in Table 2, HER2 expression was present in three out of four prolactinomas with different percentages of positive cells $(10,44$ and $27 \%)$ and also in one out of three and one out of four in $\mathrm{GH}$-secreting and non-functioning tumors respectively, with a high percentage of HER2+ cells (79\% and 98\%) and strong staining (+++) observed, which was similar to the percentage present in the ACTH-secreting adenoma (80\%). Ductal human breast carcinoma tissue samples were used as immunoreactive controls (Fig. 1A).

It has been previously reported that the phosphorylation status of HER2 protein provides more accurate information on the clinical outcome of patients undergoing trastuzumab treatment (Hudelist et al. 2006). We analyzed the expression of pHER2 by IHC in seven pituitary adenomas including two PRL, GH-secreting and non-functioning ones, which were positive or negative for HER2, and also in an ACTH-secreting pituitary adenoma (Table 2). The pHER2 was detected in the GH, ACTHsecreting and non-functioning pituitary adenomas that were highly positive for HER2, while the prolactinomas did not express pHER2. An interesting finding was the detection of pHER2 in the HER2-negative non-functioning adenoma (Fig. 1A and Table 2).

With respect to the expression of the TGFB receptors, we observed a varied expression in the different pituitary tumors. The quantification of the different receptors in non-tumor pituitaries is showed in Table 2 .

In parallel with the IHC analyses, we determined the HER2 expression in eight other patients with pituitary 
A
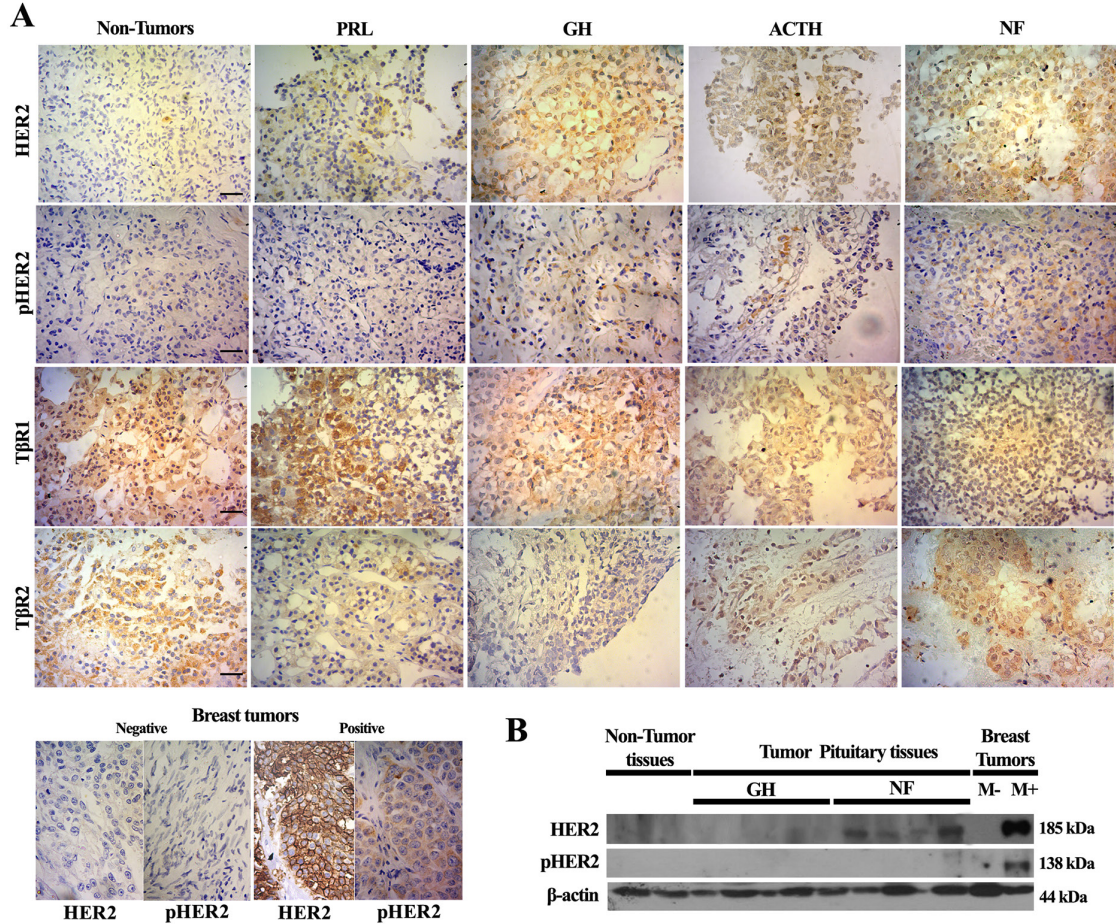

B

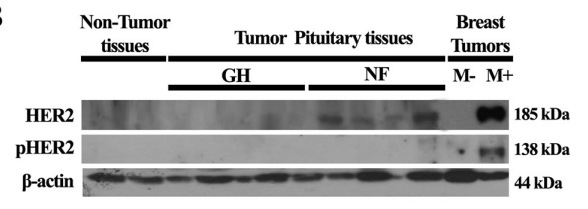

C

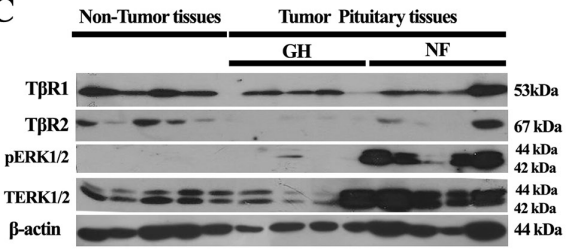

Figure 1

HER2 and TBRs expression in human pituitary adenomas. (A) Representative micrographs of the immunohistochemical analysis of HER2, pHER2, TBR1 and TBR2 expression in human non-tumor and pituitary tumor samples. HER2 positive $(\mathrm{M}+)$ and negative $(\mathrm{M}-)$ breast tumor samples were used as controls. Scale bar: $20 \mu \mathrm{m}$. Representative Western blot images of (B) HER2 and pHER2, (C) TBR1, TBR2, PERK1/2 and T-ERK1/2 expression in non-tumor pituitaries and pituitary adenomas. PRL, PRL-secreting; GH, GH-secreting; ACTH, ACTH-secreting; NF, non-secreting pituitary tumors. A full color version of this figure is available at https://doi.org/10.1530/ERC-18-0067. adenomas (four GH-secreting and four non-functioning adenomas) and five non-tumor pituitaries using WB, revealing a marked expression in pituitary tumor samples compared to non-tumor pituitaries (Fig. 1B). None of the pituitary tumor samples were observed to be positive to pHER2 (ptyr-1248 HER2) (Fig. 1B).

With respect to the TGFB receptors, we observed a reduced expression of TBR2 in pituitary tumors compared to non-tumor pituitaries (Fig. 1B), while no differences were detected for TBR1.

In addition, in order to investigate HER/ERK1/2 signaling, we determined the activation of ERK1/2 in human pituitary adenomas by WB. A significant increase in the phosphorylation of ERK1/2 was observed in the pituitary tumors analyzed compared to non-tumor tissue (Fig. 1B).

\section{Trastuzumab effect on rat pituitary tumors in vivo}

To evaluate in vivo effects of HER2 inhibition on pituitary tumor growth, we used experimental PRL pituitary tumors, which were treated with trastuzumab. First, we determined whether trastuzumab, as the primary antibody (Bussolati et al. 2005, Glazyrin et al. 2007), could bind the HER2 receptor in different human samples as well as in extracts from the rodent model (estrogen-treated Fisher rat) and rat GH3 cells. As shown in Fig. 2, trastuzumab recognized the HER2 receptor in the human tumors and in different rat samples, as was confirmed by the presence of a band at $185 \mathrm{kDa}$, which corresponded to the molecular weight of HER2 from total extract samples (Fig. 2A) and purified cell-surface proteins samples (Fig. 2B). With the aim of further strengthening these results, we investigated the trastuzumab/HER2 interactions in rat GH3 cells and in human breast tumor sample with HER2 amplification by immunoprecipitation assays. The HER2 receptor was precipitated in an immune complex with trastuzumab as primary antibody, and then immunoblotting with the anti-HER2 antibody was performed (Fig. 2C). As was expected, trastuzumab interacted with human HER2 and, also to a lesser intensity with rat HER2, indicating a possible trastuzumab/rat HER2 interaction in GH3 cells. In addition, comparing human and rat HER 2 sequences by computational analysis, three different amino acids http://erc.endocrinology-journals.org https://doi.org/10.1530/ERC-18-0067 (c) 2018 Society for Endocrinology Published by Bioscientifica Ltd. Printed in Great Britain 
A

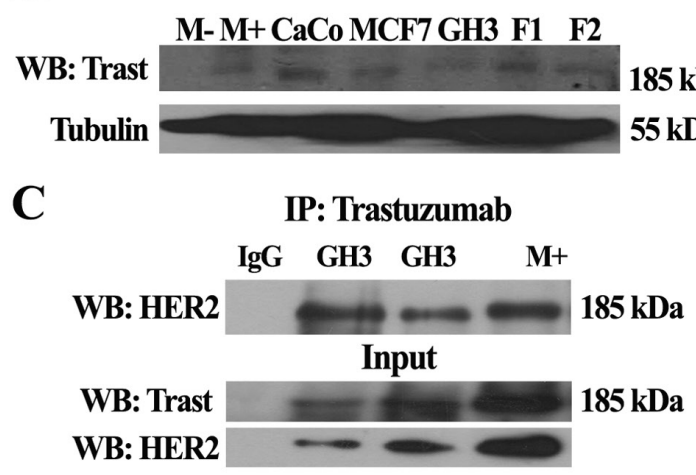

B

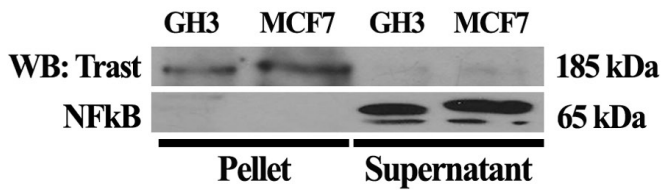

D

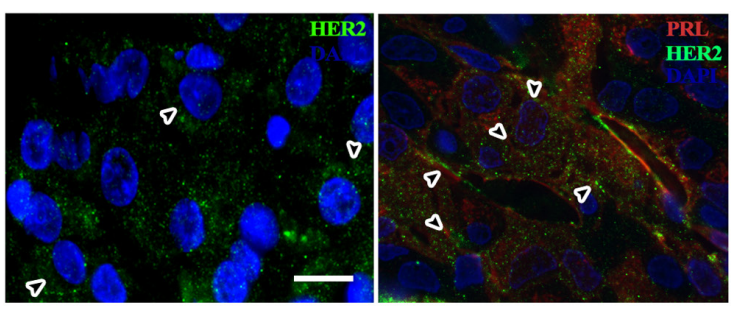

E

$\mathbf{E}+\mathbf{T}$
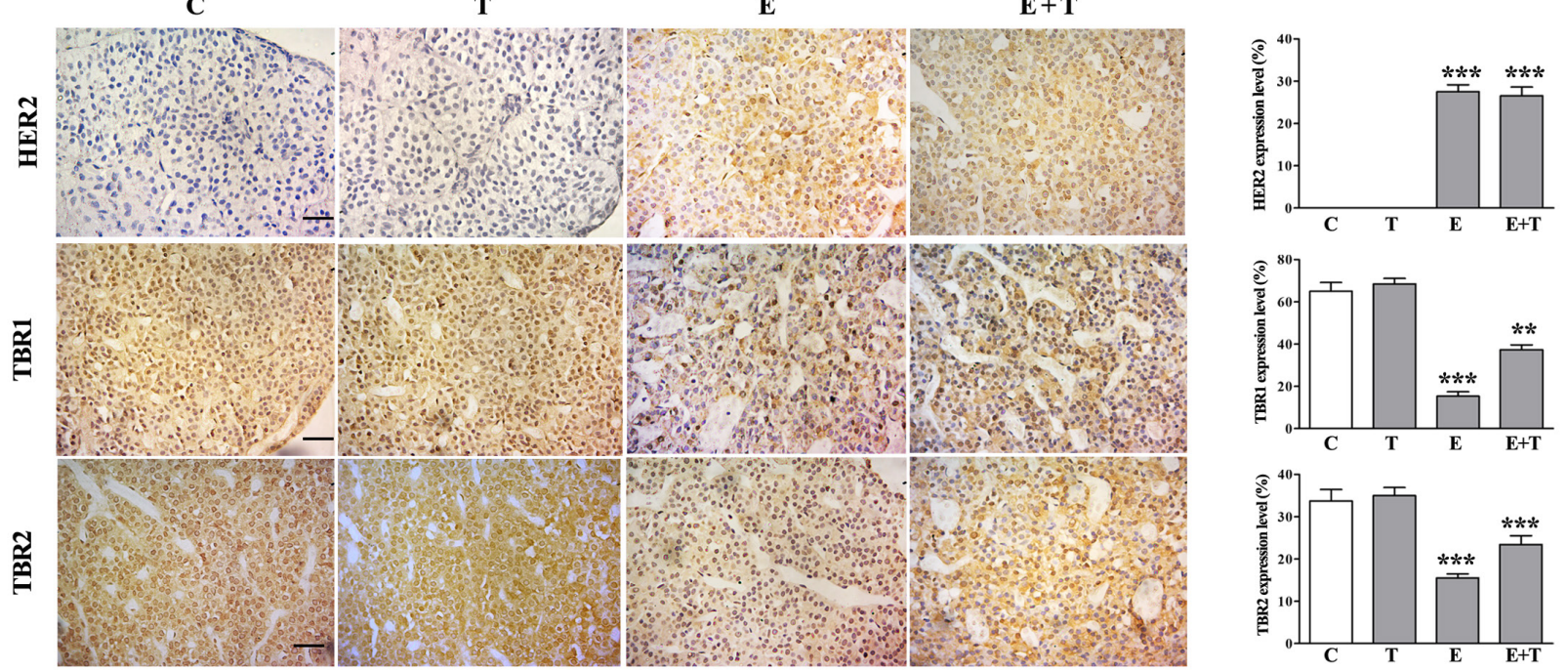

$\mathbf{E}$
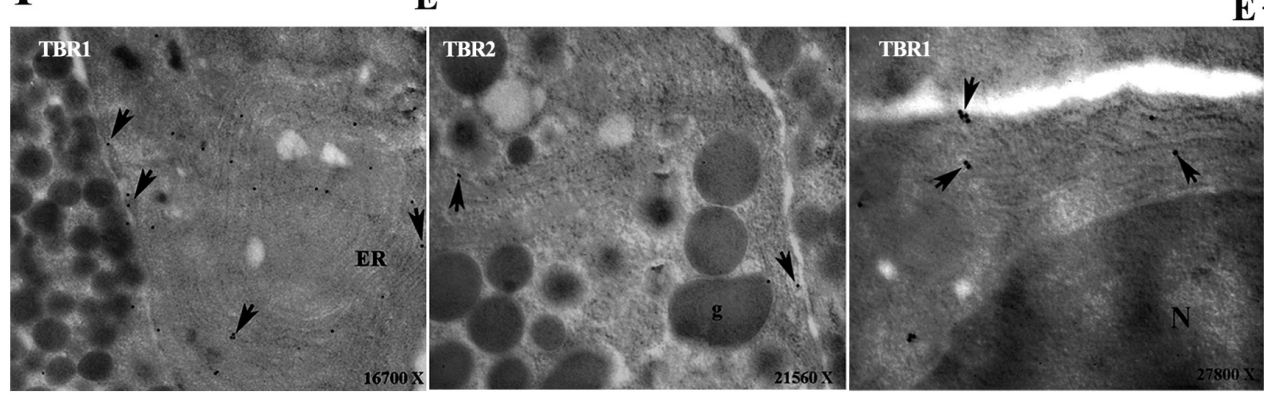

$\mathbf{E}+\mathbf{T}$

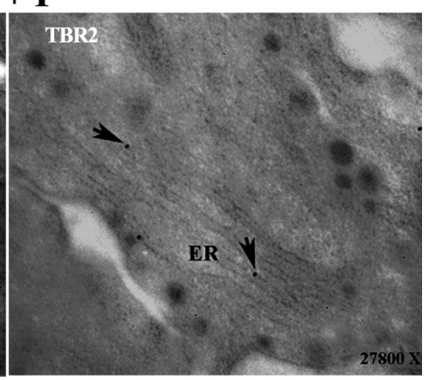

Figure 2

HER2 and TBR expression in rat pituitary tumors. (A) Western blot detection of HER2 in total extracts from rat pituitary tumors (F1 and F2) and rat GH3 pituitary tumor cells using trastuzumab as the primary antibody. Human HER2+ (M+) breast tumor, CaCo2 and MCF7 lysates were used as positive controls an human HER2- (M-) breast tumor as negative control. (B) Analysis of cell-surface proteins by biotinylation. Trastuzumab recognized the HER2 receptor in GH3 and MCF7 pellet samples, as confirmed by the presence of a band at $185 \mathrm{kDa}$, corresponding to the molecular weight of HER2, without any expression in the supernatant fractions as expected. The same result was observed using anti-HER2 as primary antibody. The expression of NFkB was used as negative control of cell surface proteins, with its presence being observed only in the supernatant fractions, indicating the purity of the isolation. (C) Trastuzumab/HER2 interactions in rat GH3 cells and in human breast tumor sample with HER2 amplification by immunoprecipitation assays. The HER2 receptor was precipitated in an immune complex with trastuzumab as primary antibody, and then anti-HER2 antibody was used for the immunoblotting. (D) Immunofluorescence staining for HER2 and PRL on cryo-sections of a rat pituitary tumor. On the left panel, white arrowheads indicate HER2 expression at the plasma membrane, while double positive (HER2-PRL) cells are shown on the right panel. Scale bar: $20 \mu \mathrm{m}$. (E) Representative micrographs and quantification of immunohistochemistry staining for HER2, TBR1 and TBR2 in the following groups: control (C), trastuzumab (T), estrogen-induced rat pituitary tumors $(E)$ and estrogen-induced rat pituitary tumors treated with trastuzumab $(6 \mathrm{mg} / \mathrm{kg})$ for the last 15 days of estrogen exposure $(E+T)$. Scale bar: $20 \mu \mathrm{m} . * * * P<0.001 \mathrm{E}$ vs C. (F) Immuno-gold labeling for TBR1 and TBR2 on E and E+T groups. Arrows show the localization of TBR1 and TBR2 at the plasma membrane and the endoplasmic reticulum (ER). A full color version of this figure is available at https://doi.org/10.1530/ERC-18-0067. 
(P571S, P572S and F573S) have been identified in the binding interface. Out of the three amino acid differences present, only P572S was predicted to be deleterious, but with a low confidence (Fig. 1 and Supplementary Table 1, see section on supplementary data given at the end of this article). The other two alterations were predicted to reduce the binding affinity, but not to be deleterious. These results show a highly conserved binding interface with three points of amino acid differences, which could predict a reduced affinity of trastuzumab by rat HER2 compared to human sHER2, in line with the immunoprecipitation assays.

In addition, we performed IHC using trastuzumab as the primary antibody for HER2 detection on cryosections from rat pituitary tumor and observed immunofluorescence in the plasma membrane and cytoplasm in rat pituitary tumor cells. Moreover, we realized double-immunofluorescence staining for HER2 (using trastuzumab) and PRL, which revealed PRLpositive cells with HER2 labeling delineating the plasma membrane, as can be observed in the Fig. 2D.

Next, we analyzed HER2 and TBR expression in experimental pituitary tumors exposed to the HER2 inhibitor by IHC with the HER2 quantification indicating an increase of expression in the $\mathrm{E}$ and $\mathrm{E}+\mathrm{T}$ groups with respect to the non-estrogen (C) and control-trastuzumab (T) groups. In addition, the quantification of both TGFB receptors (TBR1 and TBR2) showed a decrease in $\mathrm{E}$ and $\mathrm{E}+\mathrm{T}$ compared to the $\mathrm{C}$ and $\mathrm{T}$ groups (Fig. 2E).

To investigate further the results obtained by conventional IHC, we examined the subcellular localization of both TBRs in experimental pituitary tumors treated with trastuzumab by means of TEM immunogold. In the pituitary tumors without trastuzumab administration, the subcellular distribution of TBR1 and TBR2 was similar, as identified by gold particles in the plasma membrane and cytoplasm. In some cells, the cytoplasmic presence of both receptors was associated with an endoplasmic reticulum (Fig. 2F). However, the administration of the HER2 inhibitor did not induce any changes in the subcellular localization of either TGFR receptor.

Having demonstrated that the rat pituitary tumors expressed HER2, we now tested the effect of HER2 blockade on pituitary weight and cell proliferation, with cells which were immunoreactive to the mitogenic marker Ki67 in sections from three different levels of pituitary glands of each experimental group being quantified as shown in Fig. 3A and B. The pituitary tumor proliferation decreased by about 50\% (average percentages C: $1.5 \%$;
T: 1.3\%; E: 18.75\%; and E+T: 8.3\%) after treatment with trastuzumab for 2 weeks. In addition, we performed double-immunostaining of PRL, GH or ACTH hormones with Ki67 in the estrogen-treated rat group. As expected, the majority of cells identified in this experimental group were PRL+, with some of these being co-labeled with Ki67 and a few GH/Ki67-positive cells being detected. However, the ACTH cells were negative to Ki67, as shown in the Fig. 3C.

In order to elucidate whether the cell proliferation decrease observed after trastuzumab treatment could be associated with an increase in apoptosis, we used the TUNEL assay as this is useful for examining DNA fragmentation in situ, and apoptosis of pituitary cells was evaluated over histological samples of each experimental group. As shown in the Fig. 3D, no changes were observed in the number of TUNEL-positive cells in the different experimental groups.

\section{Trastuzumab effect on the protein expression of cell-cycle regulators}

The activation of the HER2 receptor promotes cell proliferation through the stimulation of proteins involved in the control of the cell cycle progression. After observing that the inhibition of HER2 decreased the proliferation of pituitary tumor cells in vivo, we investigated whether the trastuzumab effects on the expression of ERK1/2, CCND1 and CDK4. As shown in Fig. 3E, F and G, the treatment with trastuzumab significantly reduced the expression of all the mitogenic proteins analyzed, compared to the pituitary tumors from rats without treatment with the HER2 inhibitor, in agreement with the blockade observed in the cell proliferation in Fig. 2.

\section{Trastuzumab effect on TGFB1 signaling in vitro}

Having analyzed the key role of HER2 on the pituitary tumor cell proliferation, we investigated whether the trastuzumab treatment could modulate the anti-mitogenic effect of TGFB1. To carry this out, we used GH3 lactosomatotroph pituitary tumor cells and first determined the expression of HER2 by confocal microscopy (Fig. 4A) and CLEM (Fig. 4B), which allowed the simultaneous observation of a given subcellular structure. As shown in Fig. 4A and B, the receptor was localized at the plasma membrane, similar to the location found in colon cancer $\mathrm{CaCO} 2$ cells used as a positive control.

To investigate whether blocking HER2 regulated TGFB1-induced cell proliferation inhibition, we quantified 
$\mathbf{A}$

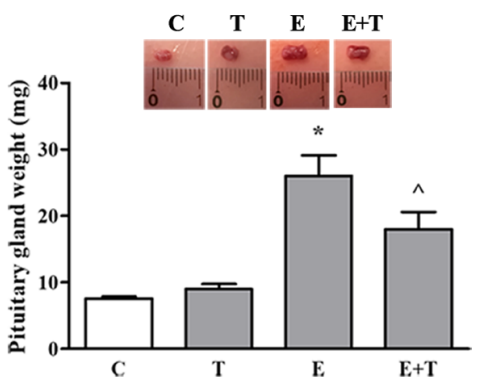

B

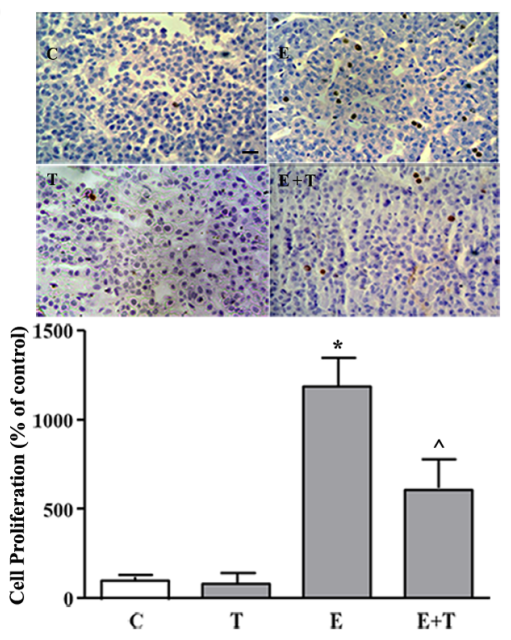

$\mathbf{E}$

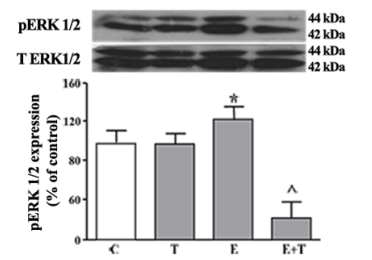

C

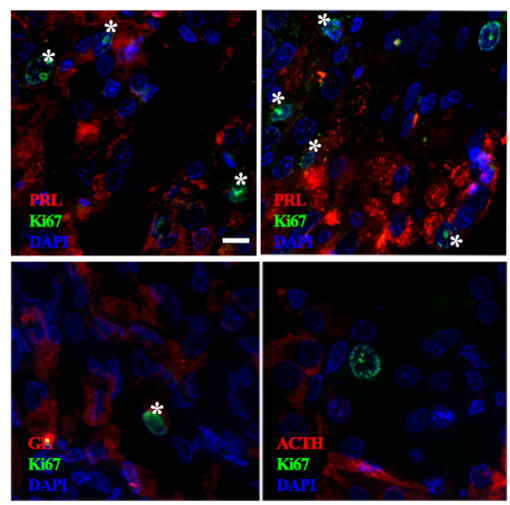

D

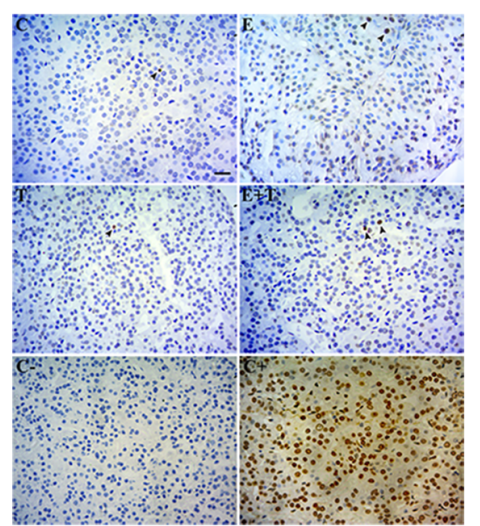

G

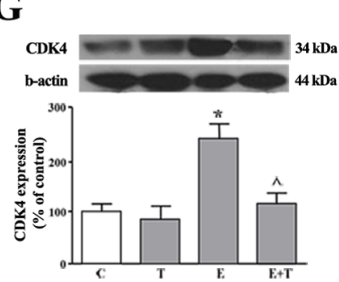

Figure 3

Effect of trastuzumab treatment on rat

experimental pituitary tumors. (A) Pituitary gland weight (mg) and the corresponding representative photographs from $\mathrm{C}, \mathrm{T}, \mathrm{E}$ and $\mathrm{E}+\mathrm{T}$ groups. ${ }^{*} P<0.05 \mathrm{E}$ vs $\mathrm{C}$ or $\mathrm{T}$ and $\wedge P<0.05 \mathrm{E}+\mathrm{T}$ vs E. (B) Representative micrographs and quantitative analysis of immunohistochemistry staining for Ki67 as a proliferation marker. Scale bar $20 \mu \mathrm{m} .{ }^{*} P<0.05 \mathrm{E}$ vs. $C$ or $\mathrm{T}$ and $\wedge P<0.05 \mathrm{E}+\mathrm{T}$ vs $E$. (C) Double-immunofluorescence staining for Ki67 (green) and PRL, GH or ACTH (red) in pituitary ultrathin cryo-sections from the $\mathrm{E}$ group. Scale bar $10 \mu \mathrm{m}$. Double-positive cells are indicated with an asterisk (*). (D) TUNEL assay from $C, T, E$ and $E+T$ groups. Arrowheads indicate apoptotic cells. Negative control (C-): pituitary gland section without corresponding primary antibody. Positive control (C+): pituitary gland section treated with DNAase I. Scale bar $20 \mu \mathrm{m}$. Western blot analysis of proliferation and cell cycle-regulator proteins. Representative panels and densitometric analysis of (E) pERK1/2-ERK 1/2, (F) CCND1, (G) CDK4 protein expression. * $P<0.05$ $E$ vs $C$ or $T$ and $\wedge P<0.05 E+T$ vs $E$. A full color version of this figure is available at https://doi. org/10.1530/ERC-18-0067. the levels of Ki67 by flow cytometry in GH3 cells exposed to TGFB1 in the presence of trastuzumab. It was observed that the treatment with TGFB1 or trastuzumab significantly decreased the cell proliferation, an effect that was potentiated when the GH3 cells were co-incubated with TGFB1 and trastuzumab (Fig. 4B). In parallel, we performed new assays using the bromodeoxyuridine (BrdU) technique, which is commonly used to measure cell proliferation. Similar results were obtained, thus confirming those acquired by Ki67 measurements (Fig. 4C).

After demonstrating the inhibition of cell proliferation by co-incubation with trastuzumab and TGFB1, we decided to study whether this effect was associated with activation of SMAD2/3. A significant increase in p-Smad2/3 expression occurred when GH3 cells were incubated with trastuzumab in the presence of TGFB1 (Fig. 4D), suggesting that activation of the canonical signal TGFB1/SMAD2/3 was inhibited by the signaling pathways activated by HER2.

To evaluate the effect of trastuzumab and TGFB1 on ERK1/2 activation, the GH3 cells were treated with the HER2 inhibitor for $30 \mathrm{~min}$ in the presence or absence of TGFB1, and their phosphorylated states were determined by WB. As shown in Fig. 4E, the analysis of pERK1/2 did not reveal any changes in the ERK1/2 pathway activation after TGFB1 stimulation. However, treatment with trastuzumab co-incubated with TGFB1 for $30 \mathrm{~min}$ induced a significant decrease in the phosphorylation of ERK1/2.

In order to try to obtain more evidence of crosstalk between HER2/ERK1/2 and TBR/SMAD2/3, we analyzed the interaction of SMAD2/3 with ERK1/2 using immunoprecipitation studies on GH3 cells treated with trastuzumab in the presence of TGF $\beta 1$ (Fig. 4F). The interaction of p-SMAD2/3-p-ERK1/2 decreased when 


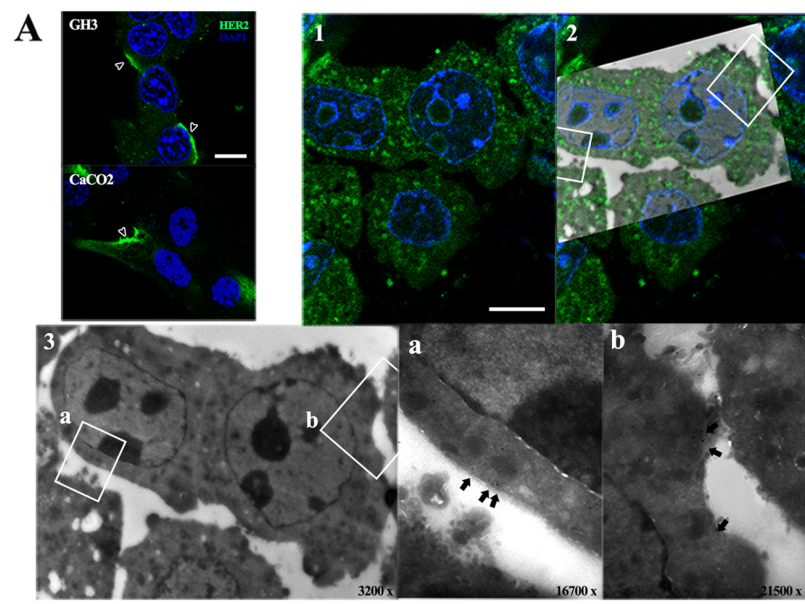

D

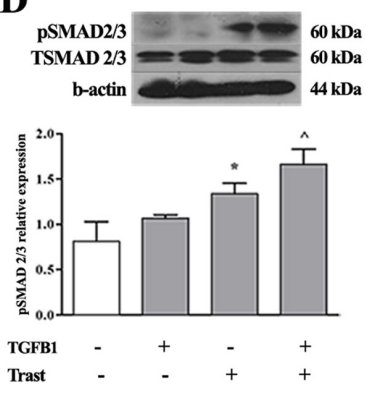

B
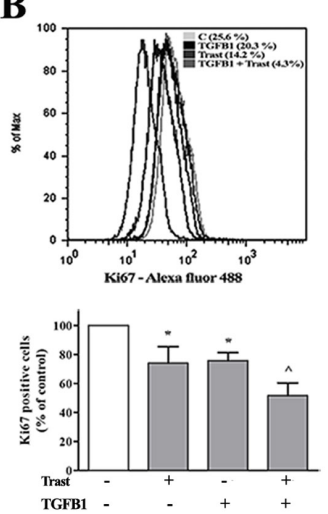

C
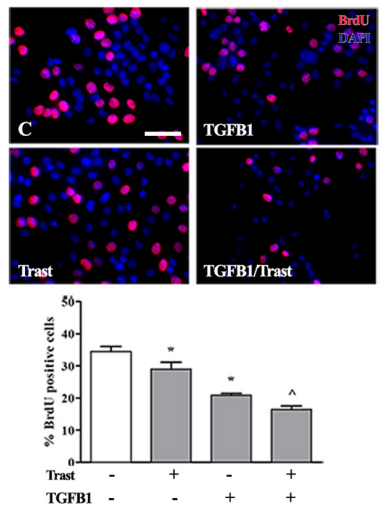

E

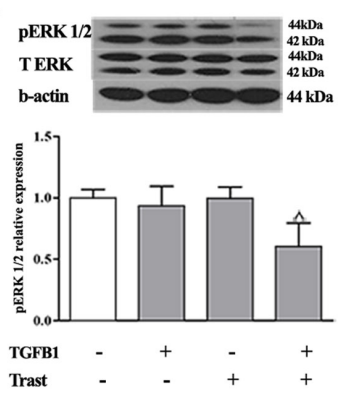

$\mathbf{F}$

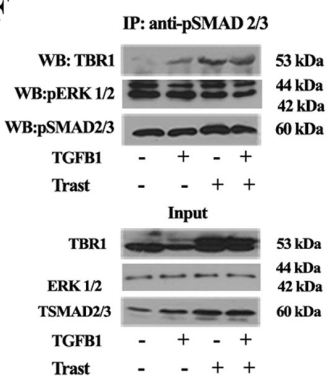

Figure 4

Effect of trastuzumab on the antiproliferative response to TGFB1. (A) Representative images of immunofluorescence labeling for HER2 in GH3 and $\mathrm{CaCO} 2$ (positive control) cell lines. White arrowheads indicate the expression of the receptor at the plasma membrane. Scale bar $10 \mu \mathrm{m}$. Correlative light and electron microscopy (CLEM): (1) Immunofluorescence images for HER2 detection in ultrathin cryo-sections of GH3 cells (scale bar 10um). (2) CLEM overlay of TEM and the corresponding FLM image. (3) TEM images for the whole section and, at higher magnification, the immuno-gold labeling for selected regions $(\mathrm{a}, \mathrm{b})$ shown by white boxes. Gold particles are indicated by black arrows. Cell proliferation analysis in GH3 cells, which were treated with TGFB1 $(4 \mathrm{ng} / \mathrm{mL})$, trastuzumab (Trast, $100 \mathrm{mM}$ ) or the combination of both factors for $24 \mathrm{~h}$. (B) Representative flow cytometry histograms and quantitative analysis of the proliferation-associated protein Ki67. (C) Representative micrographs and quantification of BrdU uptake. ${ }^{*}<0.05$ TGFB1 or Trast vs $C$, and $\wedge P<0.05$ TGFB $1+$ Trast vs TGFB 1 or Trast. TGFB 1 and MAPK-ERK1/2 signaling pathway analysis. Western blot panels and relative quantification of (D) pSMAD2/3-TSMAD2/3 and (E) pERK1/2-ERK1/2 expression from GH3 cell cultures treated with TGFB1, trastuzumab or their combination for $30 \mathrm{~min}$. (F) Immunoprecipitation (IP) of pSMAD2/3 and pERK1/2 and TBRI immunodetection in total cell extracts of GH3 cell cultures, untreated and treated for $30 \mathrm{~min}$ with trastuzumab, TGFB 1 or their combination. Input: TBRI or pERK1/2 or pSMAD2/3 antibody recognized the antigen in the total cell culture lysate. A full color version of this figure is available at https://doi.org/10.1530/ERC-18-0067.

the GH3 cells were incubated with trastuzumab in the presence of TGF $\beta 1$, compared with the treatment with TGF $\beta 1$ alone, effects that may be associated with the reduction in $\mathrm{p}$-ERK $1 / 2$ and the increase of $\mathrm{p}-\mathrm{Smad} 2 / 3$ observed in Fig. 4D-E.

The activation of $\mathrm{SMAD} 2 / 3$ can be regulated by controlling the pool of Smad2/3 available for TGFB signaling. Thus, we studied whether blocking HER2 would alter the interaction of SMAD2/3 with TBR1 by using immunoprecipitation in the GH3 cells treated with trastuzumab or TGFB1. As shown in Fig. 4F, the TGFB1 or HER2 inhibitor significantly increased the interaction between SMAD2/3 and TBR1, effects that were potentiated in GH3 cells incubated with TGFB1 in the presence of trastuzumab. These results suggest that the HER2/ERK1/2 pathway inhibited SMAD2/3 phosphorylation by interfering with its association with the TGFB receptor.

\section{Discussion}

In the present study, we demonstrated that inhibition of the HER2 receptor by trastuzumab decreased cell proliferation of pituitary tumor cells through blocking the ERK1/2 pathways and facilitating the activation of antimitogenic TGFB/SMADs signaling.

There are a wide variety of treatment options available to manage pituitary adenomas, such as pharmacotherapy with dopamine, as well as, somatostatin analogs, surgery, radiotherapy and chemotherapy. However, aggressive pituitary adenomas are notoriously difficult to manage http://erc.endocrinology-journals.org https://doi.org/10.1530/ERC-18-0067 (c) 2018 Society for Endocrinology Published by Bioscientifica Ltd. Printed in Great Britain 
due to their size, invasiveness, speed of growth and high frequency of recurrence (Buchfelder 2009). There is no clear definition of aggressive adenomas, but such tumors are generally considered (from the clinical point of view) to be those corresponding to a massive invasion of surrounding tissue, with features of rapid growth, large size, a tendency to recur rapidly, resistance to conventional treatments (including radiotherapy), and in some patients, a fatal outcome (Lloyd 2004, Buchfelder 2009). Specific biomarkers have not yet been identified that can distinguish between clinically aggressive and non-aggressive pituitary adenomas, although the antigen Ki67 proliferation index might be of use. The study of aggressiveness in pituitary tumors is of crucial importance for improving the management of patients by enhancing prognostic predictions and the effectiveness of treatments. In this sense, it is clear the need for the development of an alternative strategy for recurrent invasive adenomas or those that are resistant to conventional therapies.

We have demonstrated here the presence of HER2 in human non-functioning and in PRL-, GH- and ACTH-secreting pituitary tumors. HER2 expression was previously found to be in $31 \%$ of all pituitary tumors, $43 \%$ of non-functioning ones and $24 \%$ of functioning adenomas (Cooper et al. 2011). In different studies, HER2 expression has been confirmed in $24 \%$ of GH-secreting, $26 \%$ of PRL-secreting and 32\% of GH/PRL adenomas, as well as in $3 \%$ of the ACTH-secreting adenomas tested (Chaidarun et al. 1994, Ezzat et al. 1997, NoseAlberti et al. 1998, Botelho et al. 2006, Vlotides et al. 2009). The higher HER2 expression and proliferation index recorded in invasive adenomas compared to non-invasive ones suggests a worse prognosis in adenohypophyseal neoplasia (Nose-Alberti et al. 1998), making this receptor an attractive therapeutic target as an alternative medical therapy for pituitary tumors. The presence of intact HER2 signaling has been reported in tumors from breast cancer patients who were found to be HER2 negative by IHC. This subgroup of patients was excluded from trastuzumab treatment, although these patients may have responded to the drug (Wulfkuhle et al. 2012). On analyzing the activation of HER2, we detected pHER2 expression in pituitary adenomas positive for HER2, interestingly, in a HER2 negative non-functioning adenoma by IHC. Nevertheless, the pHER2 expression could not be observed by WB, probably due to the differences in the sample processing that enables a better exposition of the antigen in IHC. The immunodetection of pHER2 could be clinically relevant, as it has been reported that some breast cancer patients with negative
HER2 tumors present have benefited from trastuzumab (Paik et al. 2008).

Considering that the HER2 effect and signaling are mediated by the MEK/ERK1/2 cascade, we determined the activation of ERK1/2 in human pituitary tumors, with an increase in the phosphorylation of ERK1/2 in the pituitary tumors being observed compared to non-tumor tissues. These results are in agreement with a previous report that demonstrated a rise in phosphorylation, and hence, activation of MEK1/2 and ERK1/2 in all pituitary adenoma subtypes compared to normal pituitaries (Dworakowska et al. 2009). In rat prolactinoma tumor cells, treatment with the EGFR inhibitor gefitinib suppressed proliferation and ERK1/2 phosphorylation, thereby demonstrating the involvement of EGFR/ERK signaling in pituitary tumor growth (Vlotides et al. 2008). To obtain a deeper understanding of the role of the HER2/ERK pathway in pituitary tumor growth, it would be interesting to study possible crosstalk with TGFB signaling, which may help to improve the therapeutic strategy against HER2.

TGFB signaling in the development of pituitary tumors is still not fully understood and the subject of much controversy. In normal epithelial cells, TGFB1 acts as a potent tumor suppressor and prevents incipient tumors from progression to malignancy. However, due to the subsequent inactivation of TGFB signaling or key target genes, tumor cells lose their TGFB1 tumorsuppressive responses (Massague 2008). Considering that tumor cells can evade the suppressive effects of TGFB through inactivation of core components of the pathway (such as TGFB receptors), we examined the protein expression of TGFB receptors in normal and tumoral human pituitaries, with reduced TBR2 levels being observed in the tumor tissues compared to nontumoral pituitaries. These results are in agreement with previous reports that described immunoreactivity for TBR2 expression in 26 out of 48 cases of human pituitary adenomas (Fujiwara et al. 1995) and a downregulation of the TGFB/SMAD signaling cascade in dopamine-resistant prolactinomas compared to normal human anterior pituitaries (Li et al. 2015). Our results on TBRs obtained from human samples suggest that TGFB signaling may be restrained in pituitary adenomas and might be correlated with tumor growth. Consequently, recovering the capability of TGFB signaling to suppress tumor development could be a promising therapeutic strategy for pituitary tumors.

Pituitary tumors are often unresponsive to therapy, and even when an initial response is achieved, their 
recurrence is common. Bearing in mind the presence of HER2 in human pituitary tumors, we investigated the effect of specific HER2 inhibition with trastuzumab on pituitary tumor cell growth by employing two experimental approaches; an in vivo pituitary tumor model using Fisher 344 rats and in vitro experiments performed with rat GH3 lactosomatotroph pituitary tumor cell line. In this study, it was demonstrated that the human-specific HER2 monoclonal antibody (trastuzumab) recognized rat-derived HER2 in both the rodent model and GH3 cells. The analysis of cell-surface proteins by biotinylation and the theoretical model of trastuzumab/HER2 interaction showed differences between human and rat binding. The experimental PRL pituitary tumor presented a significant HER2 expression, in contrast to decreased TBR1 and TBR2 receptors. The HER2 inhibitor treatment decreased the pituitary tumor weight, cell proliferation, without inducing apoptosis, and the levels of mitogenic MAPK-ERK1/2 signaling. In addition, trastuzumab administration for two weeks in estrogen-treated rats inhibited the expression of CDK4 and CCND1, key regulators of the cell cycle progression from G1 to the S phase (Sherr \& Roberts 1995). The trastuzumab treatment in non-estrogen-treated rats did not change any of the parameters analyzed with respect to intact animals, suggesting that the trastuzumab effect takes place when there is a previous PRL pituitary tumor, which was associated with the high HER2 expression recorded in the E group.

It has been reported in transgenic mice models that CDK4 is required for both the physiological and tumorigenic control of cell cycle progression in the pituitary (Gillam et al. 2015). During the G1 phase, CDK4 is activated by CCND1 (Sherr \& Roberts 1995), which has been previously observed to be overexpressed in 22 of 45 human pituitary tumors analyzed (Simpson et al. 2001). It has been reported that lactotroph cells of CDK4-deficient mice did not proliferate in response to estrogen administration (Moons et al. 2002). In the present study, the noticeable increase of CDK4 expression observed in the E group suggests the contribution of both proteins (CCND1 and CDK4) in the regulation of tumor pituitary proliferation. Thus, these results provide evidence that the inhibition effect of trastuzumab on pituitary tumor growth in vivo can be mediated by blocking the G1/S-specific ERK1/2/CCND1/CDK4 pathway.

Although the blocking of HER2, an inhibitory effect on pituitary tumor growth has been previously described by using lapatinib (a dual tyrosine kinase inhibitor of both EGF receptors HER1 and HER2) (Fukuoka et al. 2011), this is the first study testing the specific HER2 inhibitor trastuzumab on pituitary tumor cells, which is a widely promising agent for molecular targeting therapy against breast cancer and more recently tested in patients with HER2-positive colorectal cancer (Carter et al. 1992, Ross et al. 2009, Sartore-Bianchi et al. 2016). Considering the relevance of EGF receptors in pituitary tumor progression, the EGFR antagonist lapatinib in conjunction with a dopamine agonist was evaluated in patients with dopamine analog-resistant prolactinomas and demonstrated a beneficial effect of the EGFR inhibitor in the clinical outcome, including reduced prolactin levels and tumor shrinkage (Cooper et al. 2014). In a related study performed on patients with advanced breast cancer, it was demonstrated that the lower pathological complete response rates in the lapatinib-treated group might be explained by a reduced capability of the tyrosine-kinase inhibitor to block the HER2 pathway compared with the trastuzumab antibody (Untch et al. 2012). These reports, in addition to our results, suggest that the study of the specific inhibition of HER2 by trastuzumab in pituitary tumors should be expanded, in view of the attractive therapeutic target HER2 in pituitary adenomas. It would be relevant to determine the trastuzumab/HER2 binding in human pituitary cells, which may predict the efficacy of the treatment in pre-clinical human studies. In the present study, considering the presence of HER2-positive cells in three out of four human prolactinomas, and also in the experimental pituitary tumor used, the principal target for trastuzumab treatment could be PRL-producing tumors. However, taking into account the high percentage (79\%) and strong staining (+++) of HER2 expression in one out of three GH-producing tumors, and also the presence of Ki67/GH-positive cells in the estrogen-treated rat group, we suggest that trastuzumab might have an effect on GH-secreting tumors. Future work should expand the number of cases using appropriate experimental pituitary tumor models.

Having demonstrated the anti-proliferative effect of trastuzumab in pituitary tumor growth, we investigated possible cross-talk with TGFB signaling, which has not yet been studied in pituitary tumors. Trastuzumab treatment in the presence of TGFB1 decreased GH3 cell proliferation significantly, an effect accompanied by a reduction in ERK1/2 phosphorylation, an increase in SMAD2/3 activation suggesting a negative role of the HER2/ERK1/2 pathway on the activation of SMAD2/3 in pituitary tumor cells. Although SMADs are activated by TRRI-mediated phosphorylation, their activity and 
stability are further regulated by downstream kinases of other signaling pathways (Matsuzaki 2011). In a previous report, we demonstrated that the activation of ERK1/2 by EGF blocked SMAD2/3 phosphorylation in pituitary tumor cells, and we also described a physical interaction between SMAD2/3 and ERK1/2, which interfered with the association between SMAD2/3 and TBR1 (Petiti et al. 2015). Here, we tested the interaction of SMAD2/3 with ERK1/2 and TBR1 by immunoprecipitation assays in rat GH3 cells treated with trastuzumab in the presence of TGFB1 and observed a decrease in SMAD2/3-ERK1/2 and an increase in SMAD2/3-TBR1 associations. These results suggest that the reduction of pERK1/2 in cells treated with trastuzumab in the presence of TGFB1 could be associated with a decrease in SMAD2/3-ERK1/2 interaction, which might allow the SMAD2/3 pool to become available for activation by TBRI and consequently decrease the cell proliferation. Thus, the anti-proliferative effect of trastuzumab in pituitary tumor cells may be mediated by a blockade of the HER2/ERK1/2 pathway and a consequent stimulation of the anti-mitogenic TGFB/TBR1/SMAD2/3 cascade.

In conclusion, in the present study, using in vivo and in vitro models, we demonstrated that blocking HER2 by trastuzumab inhibited pituitary tumor growth and modulated HER2/ERK1/2 signaling and consequently the anti-mitogenic TGFB/TBR/SMAD signaling (Fig. 5). Furthermore, the high expression of HER2 and ERK1/2 in contrast with the low levels of TBR2 detected in

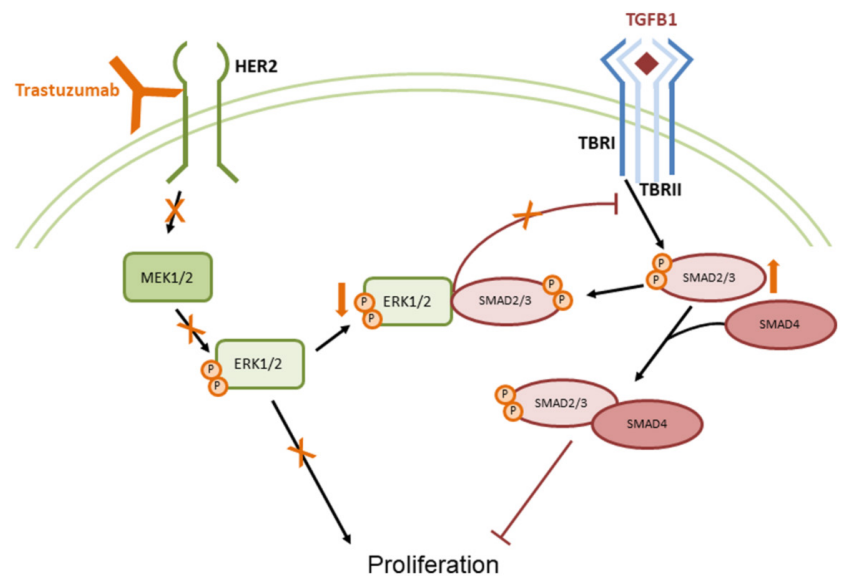

Figure 5

Model for the cross talk of HER2/ERK1/2 with TGF $\beta 1 / S M A D$ pathways in pituitary GH3 cells. Blocking HER2 by trastuzumab inhibits pituitary tumor growth and modulates HER2/ERK1/2 signaling, and consequently, the anti-mitogenic TGFB/TBR/SMAD signaling. The HER2/ERK1/2 pathway impinges on the TGF $\beta 1 / \mathrm{SMAD} 2 / 3$ signaling, thereby modulating SMAD2/3 phosphorylation. The association of SMAD2/3-ERK1/2 inhibits the $T \beta R I$-induced SMAD2/3 activation, thus counteracting the antimitogenic effect of TGF $\beta 1$. A full color version of this figure is available at https:// doi.org/10.1530/ERC-18-0067. human pituitary adenomas may have been responsible, at least in part, for the limited antiproliferative response to TGFB1detected in pituitary tumor cells (Sarkar et al. 1998). This imbalance between proliferative and antiproliferative signals in pituitary tumor cells has also been previously described in breast cancer, with HER2induced tumorigenesis in an in vivo model resulting in the loss of the TGFB signaling pathway and a lack of SMAD2 activation, accompanied by a reduction of TBR1 expression (Landis et al. 2005).

The loss of tissue homeostasis by alteration in HER2 and TBRs signaling, the frequent resistance to therapy and the early recurrence of aggressive pituitary tumors led us to investigate new pharmacological strategies. The inhibition of HER2/ERK1/2 pathway is attractive, but undoubtedly, new studies are now needed that consider a more integrated vision that involves intricate relations with other signaling pathways.

Supplementary data

This is linked to the online version of the paper at https://doi.org/10.1530/ ERC-18-0067.

\section{Declaration of interes}

The authors declare that there is no conflict of interest that could be perceived as prejudicing the impartiality of the research reported.

\section{Funding}

This work was supported by La Agencia Nacional de Promoción Científica y Tecnológica, Fondo Nacional de Ciencia y Tecnología (ANPCyT-FONCYTPICT 2014-2555), Consejo Nacional de Investigaciones Científicas y Técnicas (CONICET-PIP-Res \#154/2014) and Secretaría de Ciencia y Tecnología de la Universidad Nacional de Córdoba (SECyT-UNC Res \# 313/2016).

\section{Acknowledgements}

The authors wish to thank Lucia Artino, E E Nestor Boetto and Marcos Mirón for their excellent technical assistance. They would also like to thank native speaker Dr Paul Hobson for revising the English of the manuscript.

\section{References}

Asa SL \& Ezzat S 1998 The cytogenesis and pathogenesis of pituitary adenomas. Endocrine Reviews 19 798-827. (https://doi.org/10.1210/ edrv.19.6.0350)

Asa SL \& Ezzat S 2002 The pathogenesis of pituitary tumours. Nature Reviews Cancer 2 836-849. (https://doi.org/10.1038/nrc926)

Baselga J, Tripathy D, Mendelsohn J, Baughman S, Benz CC, Dantis L, Sklarin NT, Seidman AD, Hudis CA, Moore J, et al. 1996 Phase II study of weekly intravenous recombinant humanized anti-p185HER2 monoclonal antibody in patients with HER2/neu-overexpressing metastatic breast cancer. Journal of Clinical Oncology 14 737-744. (https://doi.org/10.1200/JCO.1996.14.3.737) 
Botelho CH, Magalhaes AV, Mello PA, Schmitt FC \& Casulari LA 2006 Expression of p53, Ki-67 and c-erb B2 in growth hormone-and/or prolactin-secreting pituitary adenomas. Arquivos de Neuro-Psiquiatria 64 60-66. (https://doi.org/10.1590/S0004-282X2006000100013)

Buchfelder M 2009 Management of aggressive pituitary adenomas: current treatment strategies. Pituitary 12 256-260. (https://doi. org/10.1007/s11102-008-0153-z)

Bussolati G, Montemurro F, Righi L, Donadio M, Aglietta M \& Sapino A 2005 A modified Trastuzumab antibody for the immunohistochemical detection of HER-2 overexpression in breast cancer. British Journal of Cancer 92 1261-1267. (https://doi. org/10.1038/sj.bjc.6602507)

Cakir M \& Grossman AB 2009 Targeting MAPK (Ras/ERK) and PI3K/Akt pathways in pituitary tumorigenesis. Expert Opinion on Therapeutic Targets 13 1121-1134. (https://doi.org/10.1517/14728220903170675)

Carter P, Presta L, Gorman CM, Ridgway JB, Henner D, Wong WL, Rowland AM, Kotts C, Carver ME \& Shepard HM 1992 Humanization of an anti-p185HER2 antibody for human cancer therapy. PNAS 89 4285-4289. (https://doi.org/10.1073/ pnas.89.10.4285)

Chaidarun SS, Eggo MC, Sheppard MC \& Stewart PM 1994 Expression of epidermal growth factor (EGF), its receptor, and related oncoprotein (erbB-2) in human pituitary tumors and response to EGF in vitro. Endocrinology 135 2012-2021. (https://doi.org/10.1210/ endo.135.5.7956924)

Cho HS, Mason K, Ramyar KX, Stanley AM, Gabelli SB, Denney DW Jr \& Leahy DJ 2003 Structure of the extracellular region of HER2 alone and in complex with the Herceptin Fab. Nature 421 756-760. (https://doi.org/10.1038/nature01392)

Cobleigh MA, Vogel CL, Tripathy D, Robert NJ, Scholl S, Fehrenbacher L, Wolter JM, Paton V, Shak S, Lieberman G, et al. 1999 Multinational study of the efficacy and safety of humanized anti-HER2 monoclonal antibody in women who have HER2-overexpressing metastatic breast cancer that has progressed after chemotherapy for metastatic disease. Journal of Clinical Oncology 17 2639-2648. (https://doi.org/10.1200/ JCO.1999.17.9.2639)

Cooper O, Vlotides G, Fukuoka H, Greene MI \& Melmed S 2011 Expression and function of ErbB receptors and ligands in the pituitary. Endocrine-Related Cancer 18 R197-R211. (https://doi. org/10.1530/ERC-11-0066)

Cooper O, Mamelak A, Bannykh S, Carmichael J, Bonert V, Lim S, Cook-Wiens G \& Ben-Shlomo A 2014 Prolactinoma ErbB receptor expression and targeted therapy for aggressive tumors. Endocrine $\mathbf{4 6}$ 318-327. (https://doi.org/10.1007/s12020-013-0093-x)

Di Ieva A, Rotondo F, Syro LV, Cusimano MD \& Kovacs K 2014 Aggressive pituitary adenomas - diagnosis and emerging treatments. Nature Reviews Endocrinology 10 423-435. (https://doi.org/10.1038/ nrendo.2014.64)

Dworakowska D, Wlodek E, Leontiou CA, Igreja S, Cakir M, Teng M, Prodromou N, Goth MI, Grozinsky-Glasberg S, Gueorguiev M, et al. 2009 Activation of RAF/MEK/ERK and PI3K/AKT/mTOR pathways in pituitary adenomas and their effects on downstream effectors. Endocrine-Related Cancer 16 1329-1338. (https://doi.org/10.1677/ERC09-0101)

Eryilmaz U, Demirci B, Aksun S, Boyacioglu M, Akgullu C, Ilgenli TF, Yalinkilinc HS \& Bilgen M 2015 S100A1 as a potential diagnostic biomarker for assessing cardiotoxicity and implications for the chemotherapy of certain cancers. PLoS ONE 10 e0145418. (https:// doi.org/10.1371/journal.pone.0145418)

Ezzat S, Zheng L, Smyth HS \& Asa SL 1997 The c-erbB-2/neu protooncogene in human pituitary tumours. Clinical Endocrinology $\mathbf{4 6}$ 599-606. (https://doi.org/10.1046/j.1365-2265.1997.1921003.x)

Ferraris J, Zarate S, Jaita G, Boutillon F, Bernadet M, Auffret J, Seilicovich A, Binart N, Goffin V \& Pisera D 2014 Prolactin induces apoptosis of lactotropes in female rodents. PLoS ONE 9 e97383. (https://doi.org/10.1371/journal.pone.0097383)
Fujiwara K, Ikeda H \& Yoshimoto T 1995 Immunohistochemical demonstration of TGF-beta-receptor type II in human pituitary adenomas. Acta Histochemica 97 445-454. (https://doi.org/10.1016/ S0065-1281(11)80071-1)

Fukuoka H, Cooper O, Mizutani J, Tong Y, Ren SG, Bannykh S \& Melmed S 2011 HER2/ErbB2 receptor signaling in rat and human prolactinoma cells: strategy for targeted prolactinoma therapy. Molecular Endocrinology 25 92-103. (https://doi.org/10.1210/me.2010-0353)

Gillam MP, Nimbalkar D, Sun L, Christov K, Ray D, Kaldis P, Liu X \& Kiyokawa H 2015 MEN1 tumorigenesis in the pituitary and pancreatic islet requires Cdk4 but not Cdk2. Oncogene 34 932-938. (https://doi.org/10.1038/onc.2014.3)

Glazyrin A, Shen X, Blanc V \& Eliason JF 2007 Direct detection of herceptin/trastuzumab binding on breast tissue sections. Journal of Histochemistry and Cytochemistry 55 25-33. (https://doi.org/10.1369/ jhc.6A7017.2006)

Guler M, Yilmaz T, Ozercan I \& Elkiran T 2009 The inhibitory effects of trastuzumab on corneal neovascularization. American Journal of Ophthalmology 147 703.e702-708.e702. (https://doi.org/10.1016/j. ajo.2008.09.022)

Hendry JM, Alvarez-Veronesi MC, Placheta E, Zhang JJ, Gordon T \& Borschel GH 2016 ErbB2 blockade with Herceptin (trastuzumab) enhances peripheral nerve regeneration after repair of acute or chronic peripheral nerve injury. Annals of Neurology 80 112-126. (https://doi.org/10.1002/ana.24688)

Hudelist G, Kostler WJ, Czerwenka K, Kubista E, Attems J, Muller R, Gschwantler-Kaulich D, Manavi M, Huber I, Hoschutzky H, et al. $2006 \mathrm{Her}-2 /$ neu and EGFR tyrosine kinase activation predict the efficacy of trastuzumab-based therapy in patients with metastatic breast cancer. International Journal of Cancer 118 1126-1134. (https://doi.org/10.1002/ijc.21492)

Humphrey W, Dalke A \& Schulten K 1996 VMD: visual molecular dynamics. Journal of Molecular Graphics 14 33-38, 27-38. (https://doi.org/10.1016/0263-7855(96)00018-5)

Ironside JW 2003 Best Practice No 172: pituitary gland pathology. Journal of Clinical Pathology 56 561-568. (https://doi.org/10.1136/ jcp.56.8.561)

Kaltsas GA \& Grossman AB 1998 Malignant pituitary tumours. Pituitary 1 69-81. (https://doi.org/10.1023/A:1009975009924)

Kaltsas GA, Nomikos P, Kontogeorgos G, Buchfelder M \& Grossman AB 2005 Clinical review: diagnosis and management of pituitary carcinomas. Journal of Clinical Endocrinology and Metabolism 90 3089-3099. (https://doi.org/10.1210/jc.2004-2231)

Kang JS, Liu C \& Derynck R 2009 New regulatory mechanisms of TGF-beta receptor function. Trends in Cell Biology 19 385-394. (https://doi.org/10.1016/j.tcb.2009.05.008)

Landis MD, Seachrist DD, Montanez-Wiscovich ME, Danielpour D \& Keri RA 2005 Gene expression profiling of cancer progression reveals intrinsic regulation of transforming growth factor-beta signaling in ErbB2/Neu-induced tumors from transgenic mice. Oncogene 24 5173-5190. (https://doi.org/10.1038/sj.onc.1208712)

Larkin MA, Blackshields G, Brown NP, Chenna R, McGettigan PA, McWilliam H, Valentin F, Wallace IM, Wilm A, Lopez R, et al. 2007 Clustal W and Clustal X version 2.0. Bioinformatics 23 2947-2948. (https://doi.org/10.1093/bioinformatics/btm404)

Li Z, Liu Q, Li C, Zong X, Bai J, Wu Y, Lan X, Yu G \& Zhang Y 2015 The role of TGF-beta/Smad signaling in dopamine agonist-resistant prolactinomas. Molecular and Cellular Endocrinology 402 64-71. (https://doi.org/10.1016/j.mce.2014.12.024)

Li M, Simonetti FL, Goncearenco A \& Panchenko AR 2016 MutaBind estimates and interprets the effects of sequence variants on proteinprotein interactions. Nucleic Acids Research 44 W494-W501. (https:// doi.org/10.1093/nar/gkw374)

Lloyd RV 2004 Advances in pituitary pathology: use of novel techniques. Frontiers of Hormone Research 32 146-174. (https://doi. org/10.1159/000079043)
2018 Society for Endocrinology Published by Bioscientifica Ltd. Printed in Great Britain 
Massague J 2008 TGFbeta in cancer. Cell 134 215-230. (https://doi. org/10.1016/j.cell.2008.07.001)

Matsuzaki K 2011 Smad phosphoisoform signaling specificity: the right place at the right time. Carcinogenesis 32 1578-1588. (https://doi. org/10.1093/carcin/bgr172)

McCubrey JA, Steelman LS, Chappell WH, Abrams SL, Franklin RA, Montalto G, Cervello M, Libra M, Candido S, Malaponte G, et al. 2012 Ras/Raf/MEK/ERK and PI3K/PTEN/Akt/mTOR cascade inhibitors: how mutations can result in therapy resistance and how to overcome resistance. Oncotarget 3 1068-1111. (https://doi. org/10.18632/oncotarget.659)

McIntyre DJ, Robinson SP, Howe FA, Griffiths JR, Ryan AJ, Blakey DC, Peers IS \& Waterton JC 2004 Single dose of the antivascular agent, ZD6126 (N-acetylcolchinol-O-phosphate), reduces perfusion for at least 96 hours in the GH3 prolactinoma rat tumor model. Neoplasia 6 150-157. (https://doi.org/10.1593/neo.03247)

Moons DS, Jirawatnotai S, Parlow AF, Gibori G, Kineman RD \& Kiyokawa H 2002 Pituitary hypoplasia and lactotroph dysfunction in mice deficient for cyclin-dependent kinase-4. Endocrinology 143 3001-3008. (https://doi.org/10.1210/endo.143.8.8956)

Nose-Alberti V, Mesquita MI, Martin LC \& Kayath MJ 1998 Adrenocorticotropin-producing pituitary carcinoma with expression of c-erbB-2 and high PCNA index: a comparative study with pituitary adenomas and normal pituitary tissues. Endocrine Pathology 9 53-62. (https://doi.org/10.1007/BF02739952)

Onishi S, Kaji T, Yamada W, Nakame K, Moriguchi T, Sugita K, Yamada K, Kawano T, Mukai M, Souda M, et al. 2016 The administration of ghrelin improved hepatocellular injury following parenteral feeding in a rat model of short bowel syndrome. Pediatric Surgery International 32 1165-1171. (https://doi.org/10.1007/s00383-016-3975-1)

Oorschot VM, Sztal TE, Bryson-Richardson RJ \& Ramm G 2014 Immuno correlative light and electron microscopy on Tokuyasu cryosections. Methods in Cell Biology 124 241-258. (https://doi.org/10.1016/B9780-12-801075-4.00011-2)

Paik S, Kim C \& Wolmark N 2008 HER2 status and benefit from adjuvant trastuzumab in breast cancer. New England Journal of Medicine 358 1409-1411. (https://doi.org/10.1056/NEJMc0801440)

Palmeri CM, Petiti JP, Sosa Ldel V, Gutierrez S, De Paul AL, Mukdsi JH \& Torres AI 2009 Bromocriptine induces parapoptosis as the main type of cell death responsible for experimental pituitary tumor shrinkage. Toxicology and Applied Pharmacology 240 55-65. (https://doi. org/10.1016/j.taap.2009.07.002)

Petiti JP, Gutierrez S, Mukdsi JH, De Paul AL \& Torres AI 2009 Specific subcellular targeting of PKCalpha and PKCepsilon in normal and tumoral lactotroph cells by PMA-mitogenic stimulus. Journal of Molecular Histology 40 417-425. (https://doi.org/10.1007/s10735-0109255-9)

Petiti JP, Sosa Ldel V, Sabatino ME, Vaca AM, Gutierrez S, De Paul AL \& Torres AI 2015 Involvement of MEK/ERK1/2 and PI3K/Akt pathways in the refractory behavior of GH3B6 pituitary tumor cells to the inhibitory effect of TGFbeta1. Endocrinology 156 534-547. (https:// doi.org/10.1210/en.2014-1070)

Roncaroli F, Nose V, Scheithauer BW, Kovacs K, Horvath E, Young WF Jr Lloyd RV, Bishop MC, Hsi B \& Fletcher JA 2003 Gonadotropic pituitary carcinoma: HER-2/neu expression and gene amplification. Report of two cases. Journal of Neurosurgery 99 402-408. (https://doi. org/10.3171/jns.2003.99.2.0402)

Roskoski R Jr 2014 The ErbB/HER family of protein-tyrosine kinases and cancer. Pharmacological Research 79 34-74. (https://doi.org/10.1016/j. phrs.2013.11.002)

Ross JS, Slodkowska EA, Symmans WF, Pusztai L, Ravdin PM \& Hortobagyi GN 2009 The HER-2 receptor and breast cancer: ten years of targeted anti-HER-2 therapy and personalized medicine. Oncologist 14 320-368. (https://doi.org/10.1634/ theoncologist.2008-0230)

Sahores A, Luque GM, Wargon V, May M, Molinolo A, BecuVillalobos D, Lanari C \& Lamb CA 2013 Novel, low cost, highly effective, handmade steroid pellets for experimental studies. PLoS ONE 8 e64049. (https://doi.org/10.1371/journal.pone.0064049)

Sarkar DK, Pastorcic M, De A, Engel M, Moses H \& Ghasemzadeh MB 1998 Role of transforming growth factor (TGF)-beta Type I and TGF-beta type II receptors in the TGF-beta1-regulated gene expression in pituitary prolactin-secreting lactotropes. Endocrinology 139 3620-3628. (https://doi.org/10.1210/endo.139.8.6135)

Sartore-Bianchi A, Trusolino L, Martino C, Bencardino K, Lonardi S, Bergamo F, Zagonel V, Leone F, Depetris I, Martinelli E, et al. 2016 Dual-targeted therapy with trastuzumab and lapatinib in treatmentrefractory, KRAS codon 12/13 wild-type, HER2-positive metastatic colorectal cancer (HERACLES): a proof-of-concept, multicentre, open-label, phase 2 trial. Lancet Oncology 17 738-746. (https://doi. org/10.1016/S1470-2045(16)00150-9)

Seshacharyulu P, Ponnusamy MP, Haridas D, Jain M, Ganti AK \& Batra SK 2012 Targeting the EGFR signaling pathway in cancer therapy. Expert Opinion on Therapeutic Targets 16 15-31. (https://doi. org/10.1517/14728222.2011.648617)

Sherr CJ \& Roberts JM 1995 Inhibitors of mammalian G1 cyclindependent kinases. Genes and Development 9 1149-1163. (https://doi. org/10.1101/gad.9.10.1149)

Simpson DJ, Fryer AA, Grossman AB, Wass JA, Pfeifer M, Kros JM, Clayton RN \& Farrell WE 2001 CCND1 (CCND1) genotype is associated with tumour grade in sporadic pituitary adenomas. Carcinogenesis 22 1801-1807. (https://doi.org/10.1093/ carcin/22.11.1801)

Sosa L del V, Gutierrez S, Petiti JP, Vaca AM, De Paul AL \& Torres AI 2013 Cooperative effect of $\mathrm{E}(2)$ and FGF2 on lactotroph proliferation triggered by signaling initiated at the plasma membrane. American Journal of Physiology: Endocrinology and Metabolism 305 E41-E49. (https://doi.org/10.1152/ajpendo.00027.2013)

Tomita T \& Gates E 1999 Pituitary adenomas and granular cell tumors. Incidence, cell type, and location of tumor in 100 pituitary glands at autopsy. American Journal of Clinical Pathology 111 817-825. (https:// doi.org/10.1093/ajcp/111.6.817)

Untch M, Loibl S, Bischoff J, Eidtmann H, Kaufmann M, Blohmer JU, Hilfrich J, Strumberg D, Fasching PA, Kreienberg R, et al. 2012 Lapatinib versus trastuzumab in combination with neoadjuvant anthracycline-taxane-based chemotherapy (GeparQuinto, GBG 44): a randomised phase 3 trial. Lancet Oncology 13 135-144. (https://doi.org/10.1016/S1470-2045(11)70397-7)

Vlotides G, Siegel E, Donangelo I, Gutman S, Ren SG \& Melmed S 2008 Rat prolactinoma cell growth regulation by epidermal growth factor receptor ligands. Cancer Research 68 6377-6386. (https://doi. org/10.1158/0008-5472.CAN-08-0508)

Vlotides G, Cooper O, Chen YH, Ren SG, Greenman Y \& Melmed S 2009 Heregulin regulates prolactinoma gene expression. Cancer Research 69 4209-4216. (https://doi.org/10.1158/0008-5472.CAN08-4934)

Wulfkuhle JD, Berg D, Wolff C, Langer R, Tran K, Illi J, Espina V, Pierobon M, Deng J, DeMichele A, et al. 2012 Molecular analysis of HER2 signaling in human breast cancer by functional protein pathway activation mapping. Clinical Cancer Research 18 64266435. (https://doi.org/10.1158/1078-0432.CCR-12-0452)

Yarden Y \& Sliwkowski MX 2001 Untangling the ErbB signalling network. Nature Reviews Molecular Cell Biology 2 127-137. (https:// doi.org/10.1038/35052073)

Received in final form 24 May 2018

Accepted 4 June 2018

Accepted Preprint published online 6 June 2018
2018 Society for Endocrinology Published by Bioscientifica Ltd. Printed in Great Britain 